\title{
The utility of 6-minute walk distance in predicting waitlist mortality for lung transplant candidates
}

\author{
Anthony Castleberry, MD, $\mathbf{M M C l}^{\mathrm{a}}$, Michael S. Mulvihill, MDa, Babatunde A. Yerokun, ${ }^{\mathrm{a}} \mathrm{D}^{\mathrm{a}}$, \\ Brian C. Gulack, MD ${ }^{\mathrm{a}}$, Brian Englum, MD ${ }^{\mathrm{a}}$, Laurie Snyder, MD, MPH' ${ }^{\mathrm{C}}$, Mathias Worni, MD, \\ MPH $^{c, d}$, Asishana Osho, MD $^{e}$, Scott Palmer, MD $^{b}$, R. Duane Davis, MD, MBA ${ }^{\dagger}$, and Matthew \\ G. Hartwig, MDa
}

aDivision of Thoracic and Cardiovascular Surgery, Department of Surgery, Duke University Medical Center, Durham, North Carolina, USA 'Division of Pulmonary, Allergy, and Critical Care Medicine, Department of Medicine, Duke University Medical Center, Durham, North Carolina, USA cDivision of Advanced Oncologic and GI Surgery, Department of Surgery, Duke University Medical Center, Durham, North Carolina, USA dDepartment of Visceral Surgery and Medicine, Inselspital, Berne University Hospital, Berne, Switzerland eDepartment of General Surgery, Massachusetts General Hospital, Boston, Massachusetts, USA ${ }^{\mathrm{f} C a r d i o v a s c u l a r ~ I n s t i t u t e, ~ F l o r i d a ~}$ Hospital, Orlando, Florida, USA

\section{Abstract}

BACKGROUND-The lung allocation score (LAS) has led to improved organ allocation for transplant candidates. At present, the 6-minute walk distance (6MWD) is treated as a binary categorical variable of whether or not a candidate can walk more than 150 feet in 6 minutes. In this study, we tested the hypothesis that 6MWD is presently under-utilized with respect to discriminatory power, and that, as a continuous variable, could better prognosticate risk of waitlist mortality.

\begin{abstract}
METHODS-A retrospective cohort analysis was performed using the Organ Procurement and Transplantation Network/United Network for Organ Sharing (OPTN/UNOS) transplant database. Candidates listed for isolated lung transplant between May 2005 and December 2011 were included. The population was stratified by $6 \mathrm{MWD}$ quartiles and unadjusted survival rates were estimated. Multivariable Cox proportional hazards modeling was used to assess the effect of 6MWD on risk of death. The Scientific Registry of Transplant Recipients (SRTR) Waitlist Risk Model was used to adjust for confounders. The optimal 6MWD for discriminative accuracy in predicting waitlist mortality was assessed by receiver-operating characteristic (ROC) curves.
\end{abstract}

RESULTS-Analysis was performed on 12,298 recipients. Recipients were segregated into quartiles by distance walked. Waitlist mortality decreased as 6MWD increased. In the

Reprint requests: Michael S. Mulvihill, MD, Department of Surgery, Duke University Medical Center 3443, Duke South 3581, Durham, NC 27710. Telephone: 919-684-8111; Fax: 919-613-9191. mike.mulvihill@dm.duke.edu.

Disclosure statement

The authors have no financial conflicts of interest to disclose. This study was supported by department funding. M.G.H., B.A.Y. and B.C.G. are supported by the Cardiothoracic Trials Network of the National Institutes of Health. 
multivariable model, significant variables included 6MWD, male gender, non-white ethnicity and restrictive lung diseases. ROC curves discriminated 6-month mortality was best at 655 feet.

CONCLUSIONS-The 6MWD is a significant predictor of waitlist mortality. A cut-off of 150 feet suboptimally identifies candidates with increased risk of mortality. A cut-off between 550 and 655 feet is more optimal if 6MWD is to be treated as a dichotomous variable. Utilization of the LAS as a continuous variable could further enhance predictive capabilities.

\section{Keywords}

lung transplantation; 6-minute walk distance; organ allocation; candidate assessment; waitlist mortality

There has been significant progress in lung transplantation since its induction in $1963 .{ }^{1}$ As of 2008, nearly 3,000 lung transplants were performed each year. ${ }^{2}$ Despite this success, there have been numerous obstacles along the way. One such issue has been the determination of an ethical and productive means of allocating donor lungs, as supply of lungs has never equaled the demand. Before 1995, lung allocation was determined purely by waitlist time, a process that led to clinicians placing candidates on waitlists earlier than necessary in order to accrue time. ${ }^{3,4}$ In 1995 , secondary to a high mortality rate among candidates with idiopathic pulmonary fibrosis (IPF), the Organ Procurement and Transplantation Network/United Network for Organ Sharing (OPTN/UNOS) added 90 days of accrued waiting time to candidates with IPF. ${ }^{3,5}$ It was not until 2005 , however, as the number of candidates on the waiting list continued to flourish, that a major overhaul was performed. ${ }^{4,6,7}$

In May 2005, the lung allocation score (LAS) was instituted as a means to further decrease waitlist mortality and, to a lesser extent, avoid transplants in candidates with a low likelihood of survival and therefore diminished utility of transplantation. ${ }^{7}$ The LAS takes into account likelihood of survival on the waiting list and post-transplant survival, and is subsequently used to compute the overall benefit of lung transplant on an individual basis. ${ }^{7}$ The estimation of these values was derived using retrospective models which found that variables such as diagnosis, forced vital capacity (FVC), age, body mass index (BMI) and New York Heart Association (NYHA) functional class, among others, were significant determinants of waitlist survival and/or post-transplant survival. ${ }^{7,8}$ Since its implementation, the LAS has (as designed) led to decreased transplant list waiting times and waitlist mortality. However, although measures of short-term survival ( 6 months and 1 year) have improved, there has been no demonstrable effect on overall long-term post-transplant survival. ${ }^{7,9-14}$ Further specific changes observed after implementation of the LAS have recently been reviewed in the latest OPTN/Scientific Registry of Transplant Recipients (SRTR) annual data report. ${ }^{7,9-14}$ Significant changes in the distribution of diagnoses among those receiving transplants has also been seen after implementation of the LAS, including a decrease in number of candidates with chronic obstructive pulmonary disease (COPD) and an increase in number of candidates with IPF. ${ }^{7,10,11}$ Further changes identified in reviews include an increase in candidates $>65$ of age receiving transplants, and a decrease in racial disparities among transplant recipients. ${ }^{15,16}$ 
Despite the successes of the LAS, there remain significant shortfalls. As stated previously, there has been no significant increase in post-transplant survival after implementation. ${ }^{9-11}$ Furthermore, there has been evidence that candidates with very high LAS scores do not necessarily have the same or increased transplant benefit as those with more moderate scores, raising the question of whether the LAS computation is appropriate. ${ }^{17}$ These findings may be secondary to how the LAS was developed, as it is weighted more heavily toward decreasing waitlist mortality than toward post-transplant survival. ${ }^{8}$ Some studies have recommended incorporation of new variables into the LAS or the adjustment of thresholds for variables already in use and, although the LAS was designed to allow modernization, few of these changes have occurred. ${ }^{8,18-20}$

One such variable that requires re-evaluation is the 6-minute walk distance (6MWD). ${ }^{21}$

Although inconsistencies in the manner of which the test is conducted can produce discrepancies in results, the test has been shown to predict mortality in numerous disease processes, including pulmonary arterial hypertension (PAH), IPF, and even liver failure..$^{22-27}$ The 6MWD also provides discriminatory power in outcomes after pediatric lung transplantation. ${ }^{28}$ It is therefore a valuable predictor of waitlist survival. The current use of the 6MWD within the LAS is as a binary categorical variable; that is, whether or not the candidate can walk $>150$ feet in 6 minutes. ${ }^{29}$ Despite its use in the LAS, studies have demonstrated that this may be too short a distance to appropriately differentiate candidates with increased risk of waitlist mortality. ${ }^{30,31}$ Due to the continued use of 150 feet as a threshold for the 6MWD within the LAS, we have investigated the 6MWD to determine the appropriate cut-off that could best distinguish candidates who have an increased risk of waitlist mortality.

\section{Methods}

The institutional review board (IRB) at Duke University approved this study before data collection.

\section{Data source}

A retrospective cohort analysis was performed using the OPTN/UNOS transplantation database. This database contains data on all transplant candidates undergoing organ donation and transplant in the United States since October 1987. The data set used for this investigation included all recipients receiving lung transplantation between October 1987 and December 2011. As of 1999, all data in the OPTN/UNOS database are collected via an internet-based database application called "UNet." Data are entered by transplant professionals. Electronic data validation and on-site audits are performed for quality assurance. $^{32}$

\section{Study design}

All transplant candidates who were listed for isolated lung transplant between May 2005 and December 2011 were included. Exclusion criteria included pediatric candidates (those $<12$ years of age) and candidates missing data for the 6MWD variable or who had " 0 " listed as the result. The primary predictor variable used in this study was 6MWD. Covariates were 
used to adjust for variation, including: age; diagnosis; gender; functional status; LAS; insurance status; education level; and other medical comorbidities. The primary outcome variable was waitlist mortality.

Recipients transplanted off the waitlist were censored at the time of transplant. Secondary analyses were performed for subgroups based on initial diagnosis.

\section{Statistical analysis}

Demographic data was compiled and described. The study population was stratified by 6MWD quartiles and unadjusted recipient survival rates were estimated using the KaplanMeier method and compared with the log-rank test. Multivariable Cox proportional hazards modeling was used to assess the effect of 6MWD on risk of death. The variables included in the SRTR Waitlist Risk Model were used to adjust for confounders. The optimal 6MWD for discriminative accuracy in predicting waitlist mortality was then assessed by constructing receiver-operating characteristic (ROC) curves. $p \leq 0.05$ was considered significant for all analyses performed in this study. Analyses were performed using JMP version 10.0 (SAS Institute, Inc., Cary, NC) and R version 2.15.1 (R Core Team, Vienna, Austria).

\section{Results}

Analysis was performed on 12,298 transplant recipients from an initial cohort of 39,968. The study inclusion/exclusion algorithm is shown in Figure 1. Demographic data from the study population are listed in Table 1. Candidates were divided into quartiles by distance walked and unadjusted Kaplan-Meier survival curves were generated (Figure 2). As 6MWD increased, a statistically significant decrease in waitlist mortality was observed. Candidates were subsequently partitioned by distance walked in intervals of 200 feet, and average waitlist mortality was assessed (Figure 3). Although no statistical significance was calculated, a general downward trend can be seen as distance walked increased.

Using multivariable Cox proportional hazards modeling, candidate characteristics were used to predict risk of waitlist mortality (Table 2). Significant variables included 6MWD, male gender, non-white ethnicity and restrictive lung diseases. ROC curves were developed to evaluate an appropriately discriminatory 6MWD cut-off for both 30-day (Figure 4) and 6month (Figure 5) mortality. The 30-day mortality was best discriminated at a distance of 550 feet, whereas 6-month mortality was best discriminated at 655 feet. As a sub-group analysis, we also analyzed 30-day mortality for IPF using the ROC curve (the most common transplant diagnosis), which resulted in a cut-off distance of 765 feet (Figure 6).

\section{Discussion}

Lung allocation has seen significant advancements over the past 3 decades, including most notably the introduction of the LAS in May 2005.,3,7 The LAS was constructed using Cox proportional hazards models for both waiting list mortality and post-transplant survival, which together help derive the transplant benefit. ${ }^{7}$ Multiple variables found to be significant predictors of both waiting list mortality and post-transplant survival were included in the equation to derive the LAS. ${ }^{33}$ Introduction of the LAS has re-distributed allografts such that 
waitlist mortality initially increased, and now varies significantly by age and diagnosis group. ${ }^{9-11}$ Furthermore, candidates with high LAS do not necessarily have the associated transplant benefit compared to candidates with a more moderate LAS, likely secondary to a stronger weighting of the LAS toward decreasing waitlist mortality over increasing posttransplant survival. ${ }^{8,12,17,34}$ Despite a built-in mechanism for the re-evaluation and addition of variables to the LAS over time, there have been few adjustments since $2005 .^{8}$

One variable of the LAS that has received attention in previous studies is use of the 6MWD. These studies have specifically hypothesized that the 6MWD cut-off may be too low to adequately predict waitlist mortality. ${ }^{31,35}$ In addition, in its present form, the distillation of the 6MWD into a dichotomous variable may under-utilize the discriminatory power of the test. The treatment of $6 \mathrm{MWD}$ as a continuous variable may add significant discriminatory power, although it may further complicate calculation of the LAS. Our findings agree with those of previous studies showing that the 6MWD is a significant predictor of mortality. ${ }^{23,25,26}$ Furthermore, our findings agree that 150 feet is too low a cut-off to properly determine which candidates have an increased risk of waitlist mortality. ${ }^{31,35}$ Through the use of ROC curves, we found that a cut-off of between 550 and 655 feet (for 30-day and 6-month mortality, respectively) is more optimal, depending on whether 30-day or 6-month mortality is used. The utility of ROC curves helps to determine how to maximize both the sensitivity and specificity of a cut-off point, thus providing a more optimal clinical value. ${ }^{36}$ Therefore, through the use of ROC curves, we have shown that a high cut-off for the 6MWD within the LAS will provide both a more sensitive and specific means of predicting waitlist mortality. Although this hypothesis has been presented in previous studies, none have taken into account a sample size of this magnitude or a scope of candidates of this breadth.

Our study also raises many questions with regard to the use of the 6MWD within the LAS. First, the dichotomization of a continuous variable reduces the power of that variable. ${ }^{37-40}$ As a binary variable, candidates are graded solely on their ability to walk a specific target distance. This severely limits the ability of the test to discriminate between candidates. For instance, there is no difference in the 6MWD result within the LAS for a candidate who can only walk a minimal distance with one who can just barely make the cut-off. Based on the data in the present study, however, if used as a continuous variable, the 6MWD would have an increased predictive ability to determine waitlist mortality up to a 6MWD of nearly 1,200 feet. After 1,200 feet, 6MWD appears to lose its discerning features for 6-month waitlist mortality.

Another question to consider is how different diagnoses affect the findings derived from the ROC curves. We demonstrated in this study that the best cut-off for the 6MWD when comparing for 30-day mortality for IPF candidates is 765 feet, compared with 550 feet for the general population. This is likely secondary to worse outcomes associated with IPF when compared with other diagnoses. ${ }^{5}$ Although diagnosis is already taken into account within the LAS, it is not known whether this satisfactorily accounts for the differences in the 6MWD, or if it should be taken into account a second time to make the 6MWD cut-off more accurate. ${ }^{7,33}$ 
Although the 6MWD was initially included in the LAS only as a predictor of waitlist mortality, we have shown in a previous investigation that the 6MWD is also significantly associated with post-transplant survival. ${ }^{7,41}$ As the goal of the LAS is to minimize waitlist mortality and avoid a futile transplant, each contributing variable should be thoroughly optimized to best provide this discriminatory power. The goal is to optimize variables with respect to prediction of both who will survive on the waitlist the longest, as well as who will survive after transplant. By minimizing waitlist mortality while maximizing post-transplant survival, the transplant benefit can be exhausted. If, however, a variable predicts both, then its use in predicting waitlist mortality may cancel out its use in predicting post-transplant survival. Furthermore, if 6MWD is a predictive variable for both outcomes, and we intend to place more importance on reducing waitlist mortality over maximizing post-transplant survival, then more discussion will be needed to determine how this impacts the most appropriate way to include 6MWD in the allocation score.

Despite the significance of our study, there are certain limitations that should be noted. First, previous data demonstrated that inconsistencies in how the 6MWD is recorded can lead to significant variation. ${ }^{22}$ Based on how the data are recorded, we cannot adjust for these variations, and it is possible that they may have an effect on outcome. Second, we cannot see trends in the LAS to determine how candidates have progressed, and where along this progression their LAS was calculated. This could theoretically lead to a higher average 6MWD since induction of the LAS, which may explain why a much lower cut-off was initially derived. Last, given the retrospective nature of this study, there remains the possibility of potential confounders for which we cannot account.

In conclusion, although use of the LAS has led to significant positive results, especially with regard to decreasing waitlist times, there are still many issues that need to be resolved. ${ }^{9,10}$ As described in our study and noted elsewhere, altering the threshold for the 6MWD as a dichotomous variable within the LAS would have better predictive ability to determine who has a higher chance of mortality while awaiting a lung transplant. ${ }^{31,35}$ Furthermore, utilizing the LAS as a continuous variable may further enhance its predictive capabilities. By improving the ability of the LAS to discriminate waitlist survival, we can ensure that utilization of the limited supply of donor lungs is as efficient as possible. Continued investigation of current and new predictors of mortality is necessary to ensure that utilization of the LAS remains as beneficial as possible.

\section{References}

1. Hardy JD, Webb WR, Dalton ML Jr, et al. Lung homotransplantation in man. JAMA. 1963; 186:1065-74. [PubMed: 14061414]

2. Christie JD, Edwards LB, Kucheryavaya AY, et al. The Registry of the International Society for Heart and Lung Transplantation: twenty-seventh official adult lung and heart-lung transplant report —2010. J Heart Lung Transplant. 2010; 29:1104-18. [PubMed: 20870165]

3. Davis SQ, Garrity ER Jr. Organ allocation in lung transplant. Chest. 2007; 132:1646-51. [PubMed: 17998365]

4. Hachem RR, Trulock EP. The new lung allocation system and its impact on waitlist characteristics and post-transplant outcomes. Semin Thorac Cardiovasc Surg. 2008; 20:139-42. [PubMed: 18707648] 
5. De Meester J, Smits JM, Persijn GG, et al. Lung transplant waiting list: differential outcome of type of end-stage lung disease, one year after registration. J Heart Lung Transplant. 1999; 18:563-71. [PubMed: 10395354]

6. Barr ML, Bourge RC, Orens JB, et al. Thoracic organ transplantation in the United States, 19942003. Am J Transplant. 2005; 5:934-49. [PubMed: 15760419]

7. Egan TM, Murray S, Bustami RT, et al. Development of the new lung allocation system in the United States. Am J Transplant. 2006; 6:1212-27. [PubMed: 16613597]

8. Eberlein M, Garrity ER, Orens JB. Lung allocation in the United States. Clin Chest Med. 2011; 32:213-22. [PubMed: 21511084]

9. De Oliveira NC, Osaki S, Maloney J, et al. Lung transplant for interstitial lung disease: outcomes before and after implementation of the United Network for Organ Sharing lung allocation scoring system. Eur J Cardiothorac Surg. 2012; 41:680-5. [PubMed: 22219404]

10. Osaki S, Maloney JD, Meyer KC, et al. The impact of the lung allocation scoring system at the single national Veterans Affairs Hospital lung transplantation program. Eur J Cardiothorac Surg. 2009; 36:497-501. [PubMed: 19394854]

11. Kozower BD, Meyers BF, Smith MA, et al. The impact of the lung allocation score on short-term transplantation outcomes: A multicenter study. J Thorac Cardiovasc Surg. 2008; 135:166-71. [PubMed: 18179935]

12. Merlo CA, Weiss ES, Orens JB, et al. Impact of U.S. Lung Allocation Score on survival after lung transplantation. J Heart Lung Transplant. 2009; 28:769-75. [PubMed: 19632571]

13. Chen H, Shiboski SC, Golden JA, et al. Impact of the lung allocation score on lung transplantation for pulmonary arterial hypertension. Am J Respir Crit Care Med. 2009; 180:468-74. [PubMed: 19520906]

14. Yusen RD, Shearon TH, Qian Y, et al. Lung transplantation in the United States, 1999-2008. Am J Transplant. 2010; 10:1047-68. [PubMed: 20420652]

15. Kilic A, Merlo CA, Conte JV, et al. Lung transplantation in patients 70 years old or older: have outcomes changed after implementation of the lung allocation score? J Thorac Cardiovasc Surg. 2012; 144:1133-8. [PubMed: 22944081]

16. Wille KM, Harrington KF, deAndrade JA, et al. Disparities in lung transplantation before and after introduction of the lung allocation score. J Heart Lung Transplant. 2013; 32:684-92. [PubMed: 23582477]

17. Russo MJ, Worku B, Iribarne A, et al. Does lung allocation score maximize survival benefit from lung transplantation? J Thorac Cardiovasc Surg. 2011; 141:1270-7. [PubMed: 21497235]

18. Loeve M, Hop WC, de Bruijne M, et al. Chest computed tomography scores are predictive of survival in patients with cystic fibrosis awaiting lung transplantation. Am J Respir Crit Care Med. 2012; 185:1096-103. [PubMed: 22403801]

19. Benza RL, Miller DP, Frost A, et al. Analysis of the lung allocation score estimation of risk of death in patients with pulmonary arterial hypertension using data from the REVEAL Registry. Transplantation. 2010; 90:298-305. [PubMed: 20559158]

20. Dudley KA, El-Chemaly S. Cardiopulmonary exercise testing in lung transplantation: a review. Pulm Med. 2012; 2012:237852. [PubMed: 22666582]

21. ATS statement: guidelines for the six-minute walk test. Am J Respir Crit Care Med. 2002; 166:111-7. [PubMed: 12091180]

22. Sciurba F, Criner GJ, Lee SM, et al. Six-minute walk distance in chronic obstructive pulmonary disease: reproducibility and effect of walking course layout and length. Am J Respir Crit Care Med. 2003; 167:1522-7. [PubMed: 12615634]

23. Gomberg-Maitland M, Glassner-Kolmin C, Watson S, et al. Survival in pulmonary arterial hypertension patients awaiting lung transplantation. J Heart Lung Transplant. 2013; 32:1179-86. [PubMed: 24074527]

24. Groepenhoff H, Vonk-Noordegraaf A, van de Veerdonk MC, et al. Prognostic relevance of changes in exercise test variables in pulmonary arterial hypertension. PLoS One. 2013; 8:e72013.

[PubMed: 24039732] 
25. Lederer DJ, Arcasoy SM, Wilt JS, et al. Six-minute-walk distance predicts waiting list survival in idiopathic pulmonary fibrosis. Am J Respir Crit Care Med. 2006; 174:659-64. [PubMed: 16778159]

26. Miyamoto S, Nagaya N, Satoh T, et al. Clinical correlates and prognostic significance of sixminute walk test in patients with primary pulmonary hypertension. Comparison with cardiopulmonary exercise testing. Am J Respir Crit Care Med. 2000; 161:487-92. [PubMed: 10673190]

27. Carey EJ, Steidley DE, Aqel BA, et al. Six-minute walk distance predicts mortality in liver transplant candidates. Liver Transpl. 2010; 16:1373-8. [PubMed: 21117246]

28. Yimlamai D, Freiberger DA, Gould A, et al. Pretransplant six-minute walk test predicts peri- and post-operative outcomes after pediatric lung transplantation. Pediatr Transplant. 2013; 17:34-40. [PubMed: 23067306]

29. Puskas JD, Oka T, Mayer E, et al. Hemodilution reduces early reperfusion injury in an ex vivo rabbit lung preservation model. Ann Thorac Surg. 1994; 57:731-5. [PubMed: 8147648]

30. Heikkila P, Parpala T, Lukkarinen O, et al. Adenovirus-mediated gene transfer into kidney glomeruli using an ex vivo and in vivo kidney perfusion system-first steps towards gene therapy of Alport syndrome. Gene Ther. 1996; 3:21-7. [PubMed: 8929908]

31. Fritz JS, Blair C, Oudiz RJ, et al. Baseline and follow-up 6-min walk distance and brain natriuretic peptide predict 2-year mortality in pulmonary arterial hypertension. Chest. 2013; 143:315-23. [PubMed: 22814814]

32. United Network for Organ Sharing. [Accessed October 24, 2013] http://www.unos.org/donation/ index.php?topic=data_collection/

33. United Network for Organ Sharing. [Accessed October 13, 2013] A guide to calculating the lung allocation score. 2009. http://www.unos.org/donation/index.php?topic=data_collection/

34. Horai T, Shigemura N, Gries C, et al. Lung transplantation for patients with high lung allocation score: single-center experience. Ann Thorac Surg. 2012; 93:1592-7. [PubMed: 22192755]

35. Kadikar A, Maurer J, Kesten S. The six-minute walk test: a guide to assessment for lung transplantation. J Heart Lung Transplant. 1997; 16:313-9. [PubMed: 9087875]

36. Grzybowski M, Younger JG. Statistical methodology: III. Receiver operating characteristic (ROC) curves. Acad Emerg Med. 1997; 4:818-26. [PubMed: 9262704]

37. Dawson NV, Weiss R. Dichotomizing continuous variables in statistical analysis: a practice to avoid. Med Decis Making. 2012; 32:225-6. [PubMed: 22457338]

38. Naggara O, Raymond J, Guilbert F, et al. Analysis by categorizing or dichotomizing continuous variables is inadvisable: an example from the natural history of unruptured aneurysms. AJNR Am J Neuroradiol. 2011; 32:437-40. [PubMed: 21330400]

39. Royston P, Altman DG, Sauerbrei W. Dichotomizing continuous predictors in multiple regression: a bad idea. Stat Med. 2006; 25:127-41. [PubMed: 16217841]

40. Cohen J. The cost of dichotomization. Appl Psychol Meas. 1983; 7:249-53.

41. Castleberry AW, Englum BR, Snyder LD, et al. Utility of six-minute walk distance in predicting outcomes after lung transplant: a nationwide survival analysis. J Heart Lung Transplant. 2013; 32(suppl):S147. 


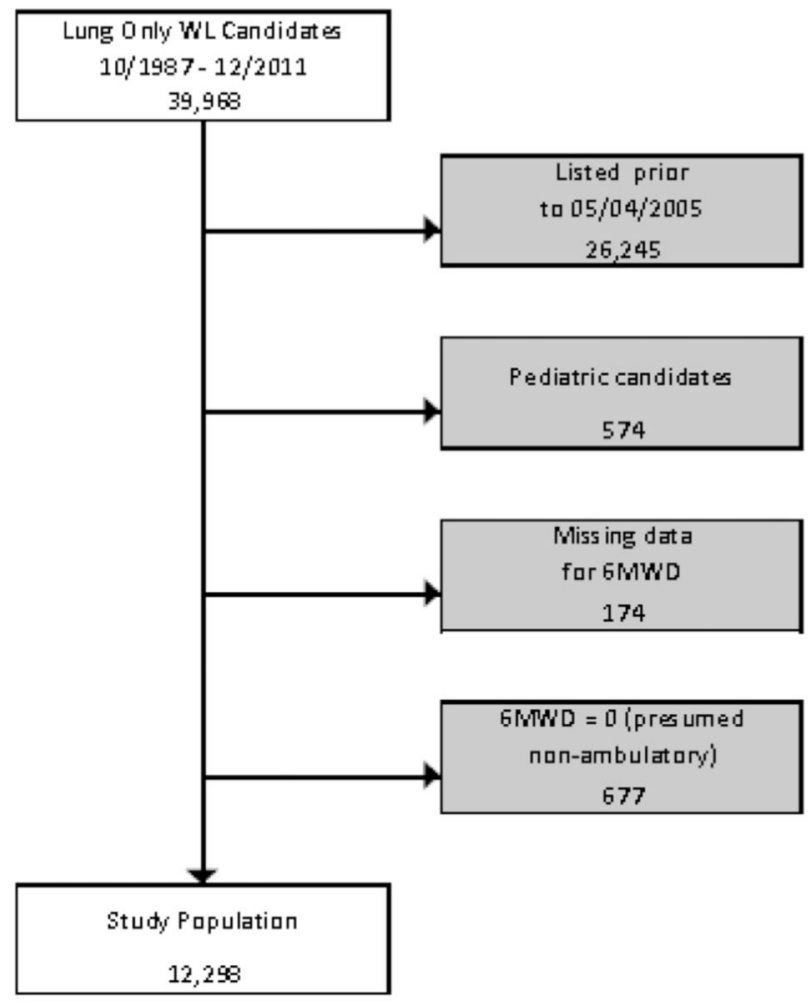

Figure 1.

STROBE diagram of candidates analyzed. STROBE, strengthening the reporting of observational studies in epidemiology. WL, waitlist; 6MWD, 6-minute walk distance. 


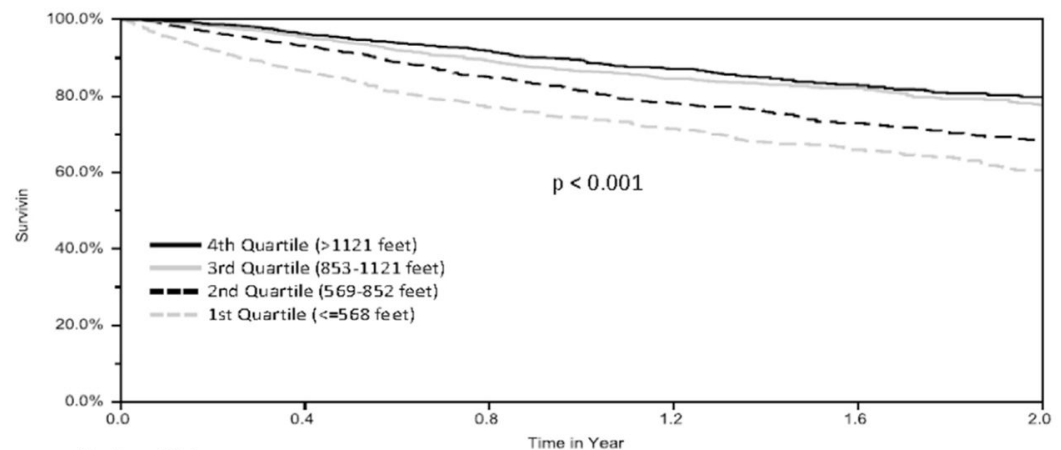

\begin{tabular}{lcccccc} 
& \multicolumn{5}{c}{ Time in Year } \\
Q4 & 3,074 & 1,720 & 992 & 643 & 437 & 310 \\
Q3 & 3,071 & 1,769 & 1,015 & 642 & 449 & 305 \\
Q2 & 3,075 & 1,668 & 878 & 537 & 359 & 253 \\
Q1 & 3,078 & 1,289 & 666 & 405 & 263 & 170 \\
\hline
\end{tabular}

Figure 2.

Kaplan-Meier curves for each 6MWD quartile. 


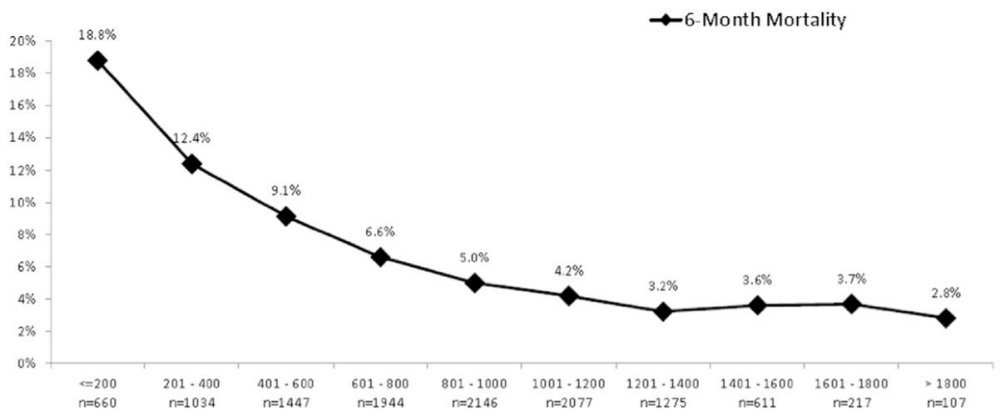

Figure 3.

Six-month waitlist mortality per interval in the 6MWD (each interval contains 200 feet). 


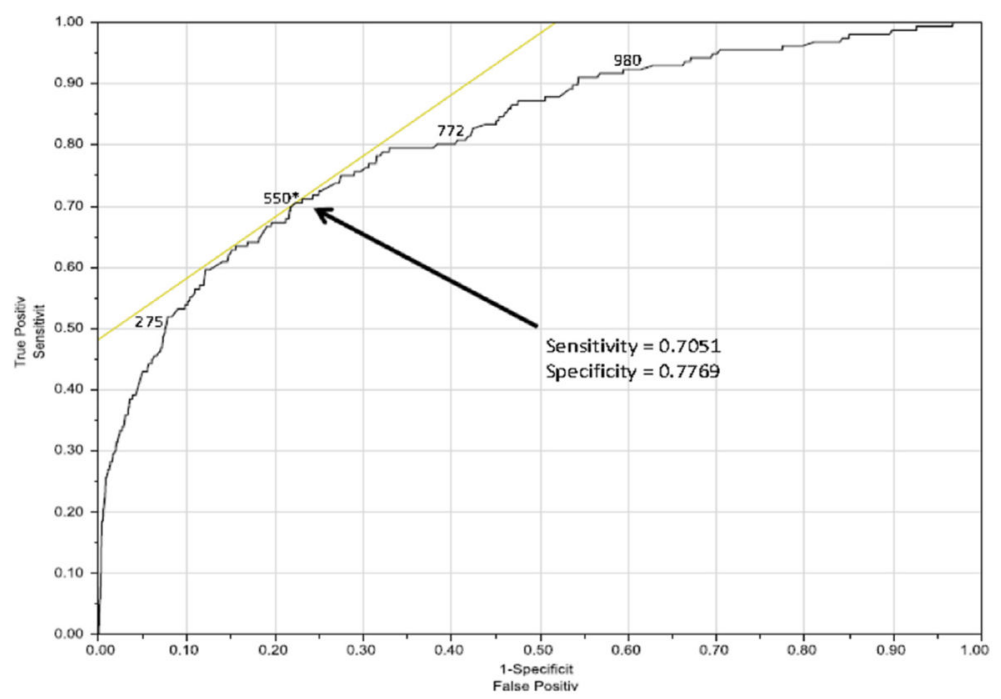

Figure 4.

ROC demonstrating optimal cut-off for 6MWD based on 30-day waitlist mortality. AUC = 0.81289 . 


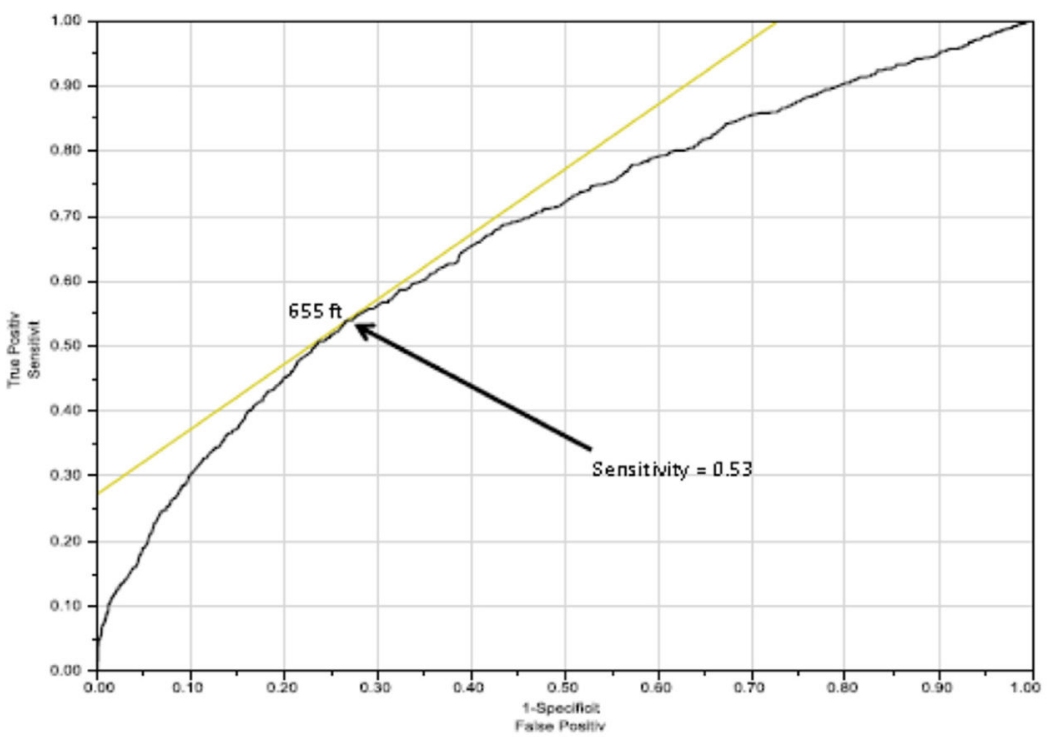

Figure 5.

ROC demonstrating optimal cut-off for 6MWD based on 6-month waitlist mortality. AUC = 0.67380 . 


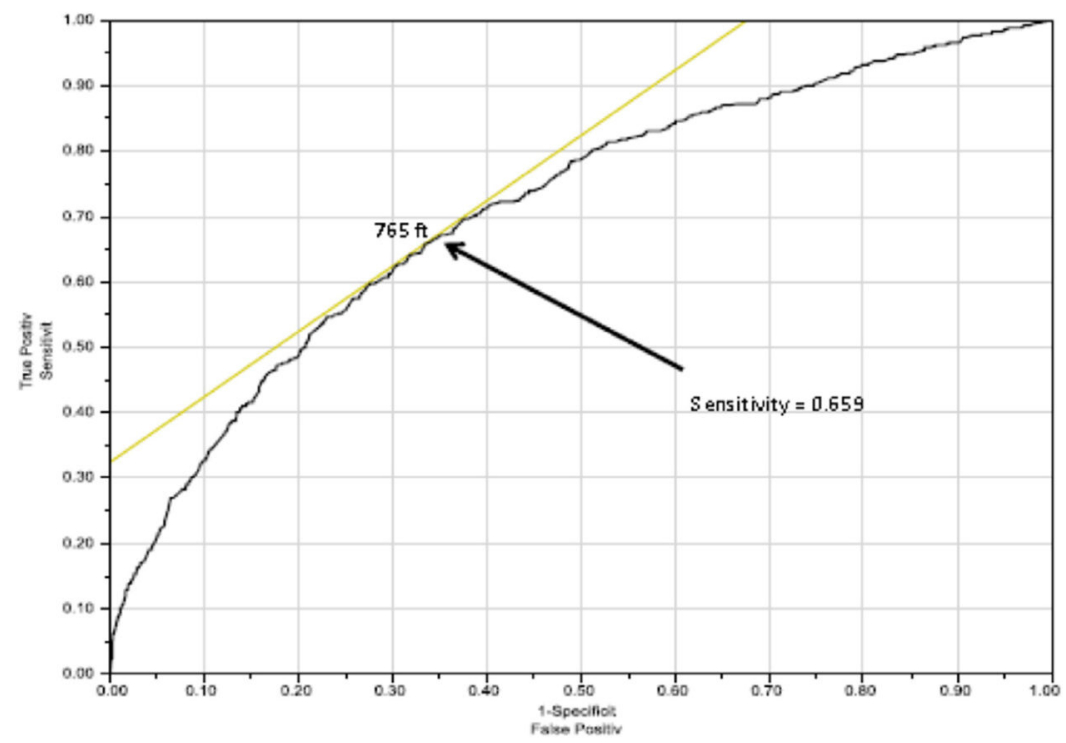

Figure 6.

ROC demonstrating optimal cut-off for 6MWD based on 30-day waitlist mortality for IPF candidates. $\mathrm{AUC}=0.71246$. 


\section{Table 1}

Baseline Characteristics $(N=12,298)$

\begin{tabular}{|c|c|}
\hline Characteristic & \\
\hline Age, in years (range) & 57 (48 to 63 ) \\
\hline Age $=60$ & $5,045(41.0 \%)$ \\
\hline Female gender & $5,654(46.0 \%)$ \\
\hline \multicolumn{2}{|l|}{ Race } \\
\hline White & $10,222(83.1 \%)$ \\
\hline Black & $1,121(9.1 \%)$ \\
\hline Hispanic & $687(5.6 \%)$ \\
\hline Asian & $188(1.5 \%)$ \\
\hline Other/unknown & $80(0.7 \%)$ \\
\hline \multicolumn{2}{|l|}{ Diagnosis } \\
\hline Obstructive & $4,317(35.1 \%)$ \\
\hline Pulmonary vascular & $553(4.5 \%)$ \\
\hline $\mathrm{CF}$ or immunodeficiency & $1,378(11.2 \%)$ \\
\hline Restrictive & $6,050(49.2 \%)$ \\
\hline \multicolumn{2}{|l|}{ Recipient comorbidities } \\
\hline Diabetes & $2,303(18.9 \%)$ \\
\hline Hypertension & 443 of $1,766(25.1 \%)$ \\
\hline Cerebrovascular disease & 16 of $1,776(0.9 \%)$ \\
\hline Creatinine at transplant $(n=1,780)$ & $0.8(0.7$ to 1.0$)$ \\
\hline BMI $\left(\mathrm{kg} / \mathrm{m}^{2}\right)$ at listing $(n=8,471)$ & 25.3 (21.4 to 28.9$)$ \\
\hline \multicolumn{2}{|l|}{ Pre-transplant status $(n=1,798)$} \\
\hline Hospitalized & 95 of $1,799(5.3 \%)$ \\
\hline Intensive care unit & 67 of $1,796(3.7 \%)$ \\
\hline Requiring life support at listing $(n=8,481)^{\mathrm{a}}$ & 233 of $8,473(2.8 \%)$ \\
\hline Requiring ventilator at listing & $219(1.8 \%)$ \\
\hline \multicolumn{2}{|l|}{ Pulmonary function and hemodynamics at listing } \\
\hline Initial lung allocation score $(n=11,631)$ & $35.9(33.0$ to 41.8$)$ \\
\hline Oxygen requirement (liters) $(n=1,652)$ & $3.0(2.0$ to 4.0$)$ \\
\hline $\mathrm{FEV}_{1}, \%$ predicted $(n=1,754)$ & $30(20$ to 49$)$ \\
\hline FVC, $\%$ predicted $(n=1,765)$ & 48 (37 to 61$)$ \\
\hline $\mathrm{FEV} / \mathrm{FVC}(n=1,753)$ & $0.73(0.43,1.06)$ \\
\hline Mean PA pressure $(\mathrm{mm} \mathrm{Hg})(n=11,085)$ & 25 (20 to 31$)$ \\
\hline \multicolumn{2}{|l|}{ Recipient insurance at time of transplant } \\
\hline Private/Self & $7,159(58.3 \%)$ \\
\hline Medicaid & $950(7.7 \%)$ \\
\hline Medicare & $3,776(30.8 \%)$ \\
\hline Other & $391(3.2 \%)$ \\
\hline \multicolumn{2}{|l|}{ Education level $(n=10,892)$} \\
\hline Grade school or lower & 342 of $10,892(3.1 \%)$ \\
\hline
\end{tabular}

J Heart Lung Transplant. Author manuscript; available in PMC 2017 July 03. 


\begin{tabular}{|ll|}
\hline Characteristic & \\
\hline High school or GED & 4,550 of $10,893(41.8 \%)$ \\
Attended college or technical school (no degree) & 2,899 of $10,890(26.6 \%)$ \\
College degree or higher & 3,101 of $10,892(28.5 \%)$ \\
Smoking history (>10 pack-years) $(n=5,684)$ & 875 of $5,686(15.4 \%)$ \\
\hline
\end{tabular}

Data expressed as median (interquartile range) for non-parametric continuous variables and as number (\%) for categorical variables. If data are missing for $>5 \%$ of the study population, the denominator is given for categorical variables and number $(n)$ given for continuous variables. BMI, body mass index; CF, cystic fibrosis; FEV 1 , forced expiratory volume at 1 second (\%); FVC, forced vital capacity; GED, general equivalency degree; PA, pulmonary artery. 
Table 2

Multivariable Cox Proportional Hazards model Predictors of Waitlist Mortality

\begin{tabular}{|llc|}
\hline & \multicolumn{2}{l|}{ Cumulative risk of death } \\
\cline { 2 - 3 } Characteristics & AHR $(\mathbf{9 5 \%} \mathbf{C I})$ & $\boldsymbol{p}$-value \\
\hline 6MWD (per 200-foot increment & $0.77(0.75$ to 0.79) & $<0.001^{a}$ \\
Recipient age (per 5-year increase) & $1.01(0.98$ to 1.03$)$ & 0.54 \\
Male gender (reference: female) & $1.16(1.04$ to 1.28$)$ & $0.006^{a}$ \\
Non-white ethnicity (reference: white) & $0.87(0.77$ to 0.99$)$ & $0.036^{a}$ \\
Restrictive lung disease (reference: obstructive) & $3.33(2.93$ to 3.79$)$ & $<0.001^{a}$ \\
Type O blood (reference: AB) & $0.78(0.59$ to 1.01$)$ & 0.061 \\
\hline
\end{tabular}

6MWD, 6-minute walking distance; AHR, adjusted hazard ratio; CI confidence interval.

${ }^{a}$ Statistically significant at $p \leq 0.05$. 